\title{
Hand hygiene as an incomplete challenge for developing countries: discussions based on knowledge and perceptions of nurses in North Cyprus example and published studies
}

\author{
Mümtaz GÜRAN ${ }^{1}$ D , Nimet İlke AKÇAY \\ Department of Microbiology, Dr. Fazil Kucuk Faculty of Medicine, Eastern Mediterranean University, Famagusta, Mersin 10, Turkey. \\ 2 Department of Bioistatistics, Dr. Fazil Kucuk Faculty of Medicine, Eastern Mediterranean University, Famagusta, Mersin 10, Turkey. \\ Corresponding Author: Mümtaz GÜRAN \\ E-mail: mumtazguran@gmail.com
}

Submitted: $03.01 .2020 \quad$ Accepted: 24.03 .2020

\begin{abstract}
Objective: In the contemporary nursing era, nurses play important roles in terms of patient care and the prevention of healthcare associated infections. Here, we aimed to discuss recommendations for developing countries by describing the level of knowledge and perceptions of hand hygiene among nurses in Northern Cyprus as an example to developing countries.

Materials and Methods: Adapted questionnaires of World Health Organization (WHO) were used for data collection and obtained data were analyzed using biostatistical methods.

Results: Among the nurses, 5.6\% had good hand hygiene knowledge. "Country of education" and "in-service education" factors were found to affect the knowledge level significantly. Positive perception level was demonstrated by $83.2 \%$ of the participants. Availability of alcohol-based hand-rub and promotion of hand hygiene by leaders were perceived as most useful actions.

Conclusion: Our study results highlighted the importance of hand hygiene education both in occupational and in-service education. Improvements are suggested in the existing continuing education programs in countries where WHO-Multimodal hand hygiene improvement strategy is not implemented.

Keywords: Hand hygiene, Clean Hands, Clean Care is Safer Care, WHO
\end{abstract}

\section{INTRODUCTION}

Healthcare-associated infections (HCAIs) are major public health problem throughout the world. HCAIs threatens the patient safety and quality of care by causing prolonged hospital stays, long-term disability, increased resistance of microorganisms to antimicrobials, high costs and increased mortality. Thus, surveillance, development and application of new preventive strategies are crucial for a safer health care. According to World Health Organization (WHO), 7\% and 10\% of hospitalized patients in developed countries and developing countries respectively, will acquire at least one health-care associated infection [1].

There are more than one mechanisms associated with the dissemination of HCAIs but hands of health care workers (HCWs) are the most risky sites for transmission of HCAIs [2]. "Savior of mothers", Ignaz Semmelweis who was one of the pioneers of antiseptic procedures suggested washing hands with chlorinated lime solutions between different operations [3]. This is widely accepted as the introduction of hand disinfection standards in 1847. Since then, many guidelines on hand hygiene $(\mathrm{HH})$ practices have been published by different organizations to increase the knowledge and awareness of health care workers[4-6]. In this content, healthcare education plays a key role for the establishment of a sustained change in the behaviors of individuals and institutions, and also for the improvement of $\mathrm{HH}$ practices when designing novel interventions.

Knowledge is one of the major factors which gives shape to the perceptions of an individual and determines how she/he will act in terms of $\mathrm{HH}$ practices. Globally, tremendous efforts are put in to counteract low knowledge or malpractice regarding $\mathrm{HH}$, but it appears that, in some parts of the world, the lack of policies has led to a lack of information on the significance of $\mathrm{HH}$.

So far, the epidemiological basis of HCAIs in Cyprus has not been studied. Furthermore,WHO Multimodal $\mathrm{HH}$ Improvement Strategy is not implemented in Northern Cyprus. Hence, exploring $\mathrm{HH}$ knowledge plays a crucial role in bridging the gap between theory and practice. Herein, we describe the level of knowledge and perceptions of $\mathrm{HH}$ among nurses in $\mathrm{N}$. Cyprus as an example of developing countries, with tailored recommendations for improvements.

How to cite this article: Güran M, Akçay Nİ. Hand hygiene as an incomplete challenge for developing countries: discussions based on knowledge and perceptions of nurses in North Cyprus example and published studies. Marmara Med J 2020;33: 67-74 doi: 10.5472/marumj.737740 


\section{MATERIALS and METHODS}

\section{Design, Setting, Sample}

This descriptive cross-sectional study was conducted in 2017, in two public hospitals in Northern Cyprus. Based on the most recent national statistical yearbook, there were 722 nurses working in public hospitals. Sample size has been calculated to be $n=184$ by using the online sample size calculator Openepi [7], where hypothesized \% frequency of the outcome factor in the population is considered to be $80 \%$ based on the survey results in the Eastern Mediterranean Region [8]. Sample group of this study included nurses working in two state hospitals who volunteered to participate.

\section{Ethical considerations}

Ethical approval of this study was obtained from Health Subcommittee of Eastern Mediterranean University Research and Publication Ethics Board with decision number 2017/40-58 and written informed consent was requested from participants before filling out the questionnaires. Only volunteer nurses who signed the informed consent form and answered the questionnaires were included in the study.

\section{Data collection}

'Perception Survey for Health-Care Workers', and 'HH Knowledge Questionnaire for Health-Care Workers' prepared by WHO and revised in 2009 [9] were used in this study. 25 knowledgerelated questions with multiple choice, yes-no or true-false answers were applied; while perception of the participants was measured via three questions with 4-point likert scale and twelve questions with 7-point likert scale answers. Both of the surveys were cross-culturally and conceptually translated. Adaptation to Turkish language included the following steps: (i) Forward translation, (ii) Expert panel Back-translation, (iii) Pre-testing and cognitive interviewing and (iv) Finalization. In addition; a demographic form was also prepared to obtain information regarding participants' age, gender, duration of practice, facility, ward and service, country of education, average number of patients (daily), and average time allocated for a patient. A count of 200 self-administrated questionnaires were proportionally distributed to the wards of the aforementioned two hospitals for voluntary participation of nurses with informed consent.

\section{Data analysis}

After data were obtained, scores for knowledge and perception were calculated for each participant by assigning one point to every correct answer in knowledge-related questions, and by summing up the scores of perception-related likert scale questions. In calculation of knowledge scores, every one of the 25 statements had the same weight, and no penalty has been applied for wrong answers. As a result, a knowledge score out of 25 have been calculated for each participant, and then it was multiplied by 4 in order to report the knowledge score out of 100 . In order to calculate the perception score for each participant, weights of the questions were assigned based on the number of likert points (1-4 in four 4-point likert scale questions, and 1-7 in twelve 7-point likert scale questions). The sum of those weights out of 96 were then converted to a perception score out of 100. Similar to the previous studies [9, 12], the levels of knowledge and perception were determined as good if the score was $\geq 75$, moderate if the score was between 50 and 74 , and poor if the score was $\leq 50$ upon 100 .

\section{Statistical analysis}

Data management was done using Microsoft EXCEL 2010 software. IBM SPSS version 21 (SPSS Inc., Chicago, IL, USA) were used for statistical analyses including calculation of the scores, descriptive analysis and hypothesis tests. In order to determine the factors affecting knowledge and perception scores, firstly normality tests were conducted for determining if parametric or nonparametric comparison tests should be applied. Since knowledge and perception scores were not normally distributed, Mann-Whitney $U$ tests were applied for factors with two categories, and Kruskal-Wallis tests were conducted to compare scores with factors of over two categories. p-value less than 0.05 were considered significant.

\section{RESULTS}

Among the 200 nurses, 125 participated in our study with a response rate of $62.5 \%$. The mean age ( \pm standard deviation) of the participants was found to be $35.67 \pm 6.68$ years. $112(89.6 \%)$ of the participants were females, and $13(10.4 \%)$ were males. The departments of the respondents are given in Table I. Answers of participants to the questions regarding whether they received a formal training in $\mathrm{HH}$ within the last three years and information about the country of institution they graduated from (i.e. from a university in Northern Cyprus or Turkey) are also given in Table I.

The calculated mean of the occupation duration of the nurses participating in this study was $12.22 \pm 7$ years, with a minimum of three and maximum of 28 years. Based on the practical experience of the participants in hospitals; they stated that the average number of patients they were dealing with every day was $17.74 \pm 6.44$, and the average length of time they spent on a patient was $6.64 \pm 3.24$ minutes.

Based on the answers of nurses participating in the study, knowledge scores were calculated on a scale of 25 . The knowledge scores ranged between eight and 20, with a mean of $14.92 \pm 2.26$. The calculated knowledge scores were then converted as out of 100; and "good, moderate and poor knowledge" frequencies were found as: $5.6 \%$ (7 of 125 nurses) of the participants had good knowledge, while $80.8 \%$ had moderate knowledge, and $13.6 \%$ had poor knowledge. The participants' knowledge scores based on different categories are given in Table I.

$\mathrm{HH}$ perception scores were calculated for each participant by summing up the scores of questions related to HCAI's and actions to improve $\mathrm{HH}$ permanently in their institutions. Obtained totals were converted to a scale out of 100 . The mean perception score was found to be $82.52 \pm 9.44$, with a median of $82.29(\min =42.71, \max =97.92)$.

The level of perception about $\mathrm{HH}$ was also calculated. Among the nurses, $83.2 \%(n=104)$ had good perception, while $16 \%$ had moderate perception, and $0.8 \%$ had poor perception. Descriptive measures and comparisons of perception scores based on demographics were variable (Table I). 
Table I. Descriptive measures and comparisons of knowledge and perception scores based on different categories.

\begin{tabular}{|c|c|c|c|c|}
\hline & Categorical Variable & Frequency & Mean \pm SD & $p$ value \\
\hline \multirow[t]{34}{*}{${ }^{1}$ Knowledge Scores } & Duration of practice & & & \multirow{4}{*}{$0.157^{\star *}$} \\
\hline & 3-11 years & $69(55.2 \%)$ & $15.26 \pm 2.25$ & \\
\hline & $12-20$ years & $38(30.4 \%)$ & $14.76 \pm 2.07$ & \\
\hline & $21-29$ years & $18(14.4 \%)$ & $13.94 \pm 2.48$ & \\
\hline & Gender & & & \multirow{3}{*}{$0.493^{*}$} \\
\hline & Male & $13(10.4 \%)$ & $14.62 \pm 2.69$ & \\
\hline & Female & $112(89.6 \%)$ & $14.96 \pm 2.22$ & \\
\hline & Department & & & \\
\hline & Urology & $20(16 \%)$ & $15.55 \pm 2.58$ & \multirow{11}{*}{$0.135^{\star *}$} \\
\hline & Pediatrics & $19(15.2 \%)$ & $15 \pm 2.69$ & \\
\hline & Surgery & $17(13.6 \%)$ & $14.24 \pm 1.48$ & \\
\hline & Cardiology & $17(13.6 \%)$ & $15.53 \pm 1.84$ & \\
\hline & Gynecology & $16(12.8 \%)$ & $15.19 \pm 2.93$ & \\
\hline & Emergency & $12(9.6 \%)$ & $15.58 \pm 1.73$ & \\
\hline & Neurosurgery & $9(7.2 \%)$ & $14.22 \pm 2.22$ & \\
\hline & Neurology & $5(4 \%)$ & $13.2 \pm 1.3$ & \\
\hline & Orthopedics & $5(4 \%)$ & $12.8 \pm 1.1$ & \\
\hline & In room service & $4(3.2 \%)$ & $15 \pm 1.41$ & \\
\hline & Pulmonary diseases & $1(0.8 \%)$ & $15 \pm 0$ & \\
\hline & Country of Education & & & \multirow{3}{*}{$0.001^{*}$} \\
\hline & NorthernCyprus & $62(49.6 \%)$ & $14.26 \pm 2.29$ & \\
\hline & Turkey & $63(50.4 \%)$ & $15.57 \pm 2.05$ & \\
\hline & \multicolumn{2}{|c|}{$\begin{array}{l}\text { Taking training on } \\
\text { HH in the last three years }\end{array}$} & & \multirow{3}{*}{$0.037^{*}$} \\
\hline & Yes & $122(97.6 \%)$ & $14.98 \pm 2.25$ & \\
\hline & No & $3(2.4 \%)$ & $12.33 \pm 1.15$ & \\
\hline & Daily hand rub use & & & \multirow{3}{*}{$0.001^{*}$} \\
\hline & Yes & $117(93.6 \%)$ & $15.09 \pm 2.23$ & \\
\hline & No & $8(6.4 \%)$ & $12.5 \pm 0.93$ & \\
\hline & Ward & & & \multirow{3}{*}{$0.179^{*}$} \\
\hline & Medical & $58(46.4 \%)$ & $15.12 \pm 2.11$ & \\
\hline & Surgical & $67(53.6 \%)$ & $14.75 \pm 2.39$ & \\
\hline & Clinic & & & \multirow{3}{*}{$0.048^{\star}$} \\
\hline & Outpatient & $48(38.4 \%)$ & $15.33 \pm 2.17$ & \\
\hline & Inpatient & $77(61.6)$ & $14.66 \pm 2.3$ & \\
\hline \multirow{28}{*}{${ }^{2}$ Perception Scores } & Duration of practice & & & \multirow{7}{*}{$0.916^{*}$} \\
\hline & 3-11 years & $69(55.2 \%)$ & $82.25 \pm 8.38$ & \\
\hline & $12-20$ years & $38(30.4 \%)$ & $82.1 \pm 9.68$ & \\
\hline & 21-29 years & $18(14.4 \%)$ & $84.43 \pm 12.69$ & \\
\hline & \multicolumn{2}{|l|}{ Gender } & & \\
\hline & Male & $13(10.4 \%)$ & $83.65 \pm 5.27$ & \\
\hline & Female & $112(89.6 \%)$ & $82.38 \pm 9.82$ & \\
\hline & \multicolumn{2}{|l|}{ Department } & & \multirow{3}{*}{$<0.001^{* *, a}$} \\
\hline & Urology & $20(16 \%)$ & $80.21 \pm 6.27$ & \\
\hline & Pediatrics & $19(15.2 \%)$ & $86.02 \pm 9.79$ & \\
\hline & Surgery & $17(13.6 \%)$ & $88.54 \pm 5.62$ & \\
\hline & Cardiology & $17(13.6 \%)$ & $82.78 \pm 3.5$ & \\
\hline & Gynecology & $16(12.8 \%)$ & $86 \pm 6.44$ & \\
\hline & Emergency & $12(9.6 \%)$ & $74.39 \pm 6.64$ & \\
\hline & Neurosurgery & $9(7.2 \%)$ & $76.85 \pm 16.46$ & \\
\hline & Neurology & $5(4 \%)$ & $82.92 \pm 13.49$ & \\
\hline & Orthopedics & $5(4 \%)$ & $69.58 \pm 12.29$ & \\
\hline & In room service & $4(3.2 \%)$ & $86.98 \pm 2.62$ & \\
\hline & Pulmonary diseases & $1(0.8 \%)$ & $92.71 \pm 0$ & \\
\hline & Country of Education & & & \\
\hline & NorthernCyprus & $62(49.6 \%)$ & $84.74 \pm 8.25$ & $0.037^{*}$ \\
\hline & Turkey & $63(50.4 \%)$ & $80.32 \pm 10.08$ & \\
\hline & Ward & & & \\
\hline & Medical & $58(46.4 \%)$ & $82.58 \pm 8.75$ & $0.915^{*}$ \\
\hline & Surgical & $67(53.6 \%)$ & $82.46 \pm 10.07$ & \\
\hline & Clinic & & & \\
\hline & Outpatient & $48(38.4 \%)$ & $81.97 \pm 8.53$ & $0.399^{*}$ \\
\hline & Inpatient & $77(61.6)$ & $82.86 \pm 10.01$ & \\
\hline
\end{tabular}

${ }^{1}$ Knowledge scores (out of 25) based on different categories. ${ }^{2}$ Perception scores (out of 100) based on different categories. ${ }^{*}$ Mann Whitney U test, ${ }^{* *}$ Kruskal-Wallis test, a Significance between categories; Orthopedics-Surgery ( $\mathrm{p}=0.014)$, Emergency-Gynecology $(\mathrm{p}=0.035)$, Emergency-Pediatrics $(\mathrm{p}=0.003)$, Emergency-Surgery $(\mathrm{p}<0.001)$, Urology-Surgery $(\mathrm{p}=0.034)$ 
Frequency and percentages of true and false answers to questions related to routes of cross-transmission and $\mathrm{HH}$ methodologies from 'HH Knowledge Questionnaire for Health-Care Workers' are shown in Table II.

Table II. Frequency and percentages of true and false answers to questions related to routes of cross-transmission and $\mathrm{HH}$ methodologies from 'HH Knowledge Questionnaire for Health-Care Workers'.

\begin{tabular}{|c|c|c|c|c|}
\hline \multicolumn{2}{|c|}{ Description } & Correct Answer & Frequency & Percentage \\
\hline \multirow{4}{*}{$\begin{array}{l}\text { Main route of cross-transmission of potentially } \\
\text { harmful germs between patients in a health-care } \\
\text { facility }\end{array}$} & Health-care workers' hands when not clean & true & $104 / 125$ & $83.2 \%$ \\
\hline & Air circulating in the hospital & false & $7 / 125$ & $5.6 \%$ \\
\hline & Patients' exposure to colonized surfaces & false & $6 / 125$ & $4.8 \%$ \\
\hline & $\begin{array}{l}\text { Sharing non-invasive objects between } \\
\text { patients }\end{array}$ & false & $8 / 125$ & $6.4 \%$ \\
\hline \multirow{4}{*}{$\begin{array}{l}\text { Most frequent source of germs responsible for } \\
\text { health care-associated infections }\end{array}$} & The hospital's water system & false & $0 / 125$ & $0 \%$ \\
\hline & The hospital air & false & $16 / 125$ & $12.8 \%$ \\
\hline & $\begin{array}{l}\text { Germs already present on or within the } \\
\text { patient }\end{array}$ & true & $24 / 125$ & $19.2 \%$ \\
\hline & The hospital environment (surfaces) & false & $85 / 125$ & $68 \%$ \\
\hline \multirow{4}{*}{$\begin{array}{l}\mathrm{HH} \text { actions preventing transmission of germs to the } \\
\text { patient }\end{array}$} & Before touching a patient & yes & $125 / 125$ & $100 \%$ \\
\hline & $\begin{array}{l}\text { Immediately after a risk of body fluid } \\
\text { exposure }\end{array}$ & no & $37 / 125$ & $29.6 \%$ \\
\hline & $\begin{array}{l}\text { After exposure to the immediate } \\
\text { surroundings of a patient }\end{array}$ & no & $35 / 125$ & $28 \%$ \\
\hline & Immediately before a clean/aseptic procedure & yes & $100 / 125$ & $80 \%$ \\
\hline \multirow{4}{*}{$\begin{array}{l}\mathrm{HH} \text { actions preventing transmission of germs to the } \\
\text { health-care worker }\end{array}$} & After touching a patient & yes & $107 / 125$ & $85.6 \%$ \\
\hline & $\begin{array}{l}\text { Immediately after a risk of body fluid } \\
\text { exposure }\end{array}$ & yes & $113 / 125$ & $90.4 \%$ \\
\hline & Immediately before a clean/aseptic procedure & no & $32 / 125$ & $25.6 \%$ \\
\hline & $\begin{array}{l}\text { After exposure to the immediate } \\
\text { surroundings of a patient }\end{array}$ & yes & $59 / 125$ & $47.2 \%$ \\
\hline \multirow{4}{*}{$\begin{array}{l}\text { Knowledge on when using alcohol-based hand rub } \\
\text { and handwashing with soap }\end{array}$} & $\begin{array}{l}\text { Handrubbing is more rapid for hand } \\
\text { cleansing than handwashing }\end{array}$ & true & $108 / 125$ & $86.4 \%$ \\
\hline & $\begin{array}{l}\text { Handrubbing causes skin dryness more than } \\
\text { handwashing }\end{array}$ & false & $17 / 125$ & $13.6 \%$ \\
\hline & $\begin{array}{l}\text { Handrubbing is more effective against germs } \\
\text { than handwashing }\end{array}$ & true & $91 / 125$ & $72.8 \%$ \\
\hline & $\begin{array}{l}\text { Handwashing and handrubbing are } \\
\text { recommended to be performed in sequence }\end{array}$ & false & $29 / 125$ & $23.2 \%$ \\
\hline \multirow{4}{*}{$\begin{array}{l}\text { Knowledge on minimal time needed for alcohol- } \\
\text { based hand rub to kill most germs on your hands }\end{array}$} & 20 seconds & true & $78 / 125$ & $62.4 \%$ \\
\hline & 3 seconds & false & 0 & $0 \%$ \\
\hline & 1 minute & false & $41 / 125$ & $32.8 \%$ \\
\hline & 10 seconds & false & $5 / 125$ & $4 \%$ \\
\hline \multirow{6}{*}{$\begin{array}{l}\text { Knowledge on the required } \mathrm{HH} \text { method specific } \\
\text { situations }\end{array}$} & Before palpation of the abdomen & rubbing & $80 / 125$ & $64 \%$ \\
\hline & Before giving an injection & rubbing & $63 / 125$ & $50.4 \%$ \\
\hline & After emptying a bedpan & rubbing & $43 / 125$ & $34.4 \%$ \\
\hline & After removing examination gloves & rubbing & $66 / 125$ & $52.8 \%$ \\
\hline & After making a patient's bed & rubbing & $60 / 125$ & $48 \%$ \\
\hline & After visible exposure to blood & washing & $59 / 125$ & $47.2 \%$ \\
\hline \multirow{4}{*}{$\begin{array}{l}\text { Avoided cosmetics, as associated with increased } \\
\text { likelihood of colonization of hands with harmful } \\
\text { germs }\end{array}$} & Wearing jewellery & yes & $108 / 125$ & $86.4 \%$ \\
\hline & Damaged skin & yes & $123 / 125$ & $98.4 \%$ \\
\hline & Artificial fingernails & yes & $118 / 125$ & $94.4 \%$ \\
\hline & Regular use of a hand cream & no & $86 / 125$ & $68.8 \%$ \\
\hline
\end{tabular}


Frequency, percentage, and 95\% Confidence Intervals of high/ very high answers (from a 4-point likert scale) and selection of answers $\geq 6$ (from a 7-point likert scale) for questions related to HCAIs and $\mathrm{HH}$ effectiveness from 'Perception Survey for Health-Care Workers' are shown in Table III.

Table III. Frequency, percentage, and 95\% Confidence Intervals of high/very high answers from a 4-point likert scale and selection of answers $\geq 6$ from a 7-point likert scale for questions related to HCAIs and HH effectiveness from 'Perception Survey for Health-Care Workers'.

\begin{tabular}{|c|c|c|c|}
\hline Description & Question & Frequency & $\%(95 \% \mathrm{CI})$ \\
\hline \multirow[t]{3}{*}{$\begin{array}{l}\text { Questions related to HCAIs and HH effectiveness based } \\
\text { on answers high/very high (3/4) from a 4-point likert } \\
\text { scale. }\end{array}$} & $\begin{array}{l}\text { Impact of HCAIs on patient outcome (high/ } \\
\text { very high) }\end{array}$ & $103 / 125$ & $82.4 \%(76,88.8)$ \\
\hline & $\begin{array}{l}\text { HH effectiveness in preventing HCAIs (high/ } \\
\text { very high) }\end{array}$ & $116 / 125$ & $92.8 \%(88,96.8)$ \\
\hline & $\begin{array}{l}\text { Importance in the ward of hand hygiene with } \\
\text { respect to all patient safety issues (high/very } \\
\text { high) }\end{array}$ & $65 / 125$ & $52 \%(43.2,61.6)$ \\
\hline \multirow[t]{12}{*}{$\begin{array}{l}\text { Questions related to actions to improve } \mathrm{HH} \text { and other } \\
\text { components of } \mathrm{HH} \text { management based on the selection of } \\
\text { answers with scores } \geq 6 \text { from a 7-point likert scale. }\end{array}$} & $\begin{array}{l}\text { Leaders and senior managers support and } \\
\text { openly promote } \mathrm{HH}\end{array}$ & $118 / 125$ & $94.4 \%(90.4,97.6)$ \\
\hline & $\begin{array}{l}\text { Alcohol-based handrub always available at each } \\
\text { point of care }\end{array}$ & $119 / 125$ & $95.2 \%(90.4,98.4)$ \\
\hline & $\begin{array}{l}\text { Hand-hygiene posters are displayed at point of } \\
\text { care as reminders }\end{array}$ & $107 / 125$ & $85.6 \%(79.2,91.2)$ \\
\hline & $\begin{array}{l}\text { Each healthcare worker receives education on } \\
\mathrm{HH}\end{array}$ & $117 / 125$ & $93.6 \%(88.8,97.6)$ \\
\hline & $\begin{array}{l}\text { Clear and simple instructions for } \mathrm{HH} \text { are made } \\
\text { visible for every healthcare worker }\end{array}$ & $113 / 125$ & $90.4 \%(84.8,95.2)$ \\
\hline & $\begin{array}{l}\text { Healthcare workers regularly receive feedback } \\
\text { on their HH performance }\end{array}$ & $111 / 125$ & $88.8 \%(83.2,94.4)$ \\
\hline & $\begin{array}{l}\text { You always perform } \mathrm{HH} \text { as recommended } \\
\text { (being a good example for your colleagues) }\end{array}$ & $114 / 125$ & $91.2 \%(85.6,96)$ \\
\hline & $\begin{array}{l}\text { Patients/parents are invited to remind } \\
\text { healthcare workers to perform } \mathrm{HH}\end{array}$ & $113 / 125$ & $90.4 \%(84.8,95.2)$ \\
\hline & $\begin{array}{l}\text { Importance that the head of the ward places on } \\
\text { the fact that HCWs perform optimal HH (high/ } \\
\text { very high) }\end{array}$ & $83 / 125$ & $66.4 \%(57.6,75.2)$ \\
\hline & $\begin{array}{l}\text { Importance that your colleagues places on the } \\
\text { fact that HCWs perform optimal HH (high/ } \\
\text { very high) }\end{array}$ & $61 / 125$ & $48.8 \%(40,57.6)$ \\
\hline & $\begin{array}{l}\text { Importance that the patients/parents places on } \\
\text { the fact that HCWs perform optimal HH (high/ } \\
\text { very high) }\end{array}$ & $28 / 125$ & $22.4 \%(16,29.6)$ \\
\hline & $\begin{array}{l}\text { Effort required to perform good HH when } \\
\text { caring for patients (high/very high) }\end{array}$ & $28 / 125$ & $22.4 \%(15.2,29.6)$ \\
\hline
\end{tabular}




\section{DISCUSSION}

This study demonstrates low rates of "good HH knowledge," despite in - service education among nurses in NorthernCyprus. Therefore, the quality and effectiveness of in - service education activities should be re-evaluated and standardized. Also, our analysis shows that poor $\mathrm{HH}$ knowledge is strongly associated with educational background and interestingly with the country of education. Even though, the perception of $\mathrm{HH}$ effectiveness in patient safety was high, it was the least important among other safety issues for nurses participating in our study. Our study participants perceived promotion of $\mathrm{HH}$ by leaders/senior managers as the most useful action to improve adherence to $\mathrm{HH}$ practices along with alcohol-based hand-rub use.

World Health Organization's "Clean Care is Safer Care" was launched in October 2005 as the first Global Patient Safety Challenge, aimed at reducing HCAI worldwide. Global promotion of $\mathrm{HH}$ was one of the most important actions within "Clean Care is Safer Care" campaign [6]. In order to provide a safer care for patients, healthcare workers must have good $\mathrm{HH}$ knowledge and follow the $\mathrm{HH}$ guidelines. There are studies which demonstrate the necessity of a high level of knowledge for good $\mathrm{HH}$ practices, despite the fact that practices may not always reflect their knowledge [10-13]. As a limitation, practices were not observed in our study, but our results did not show an adequate level of $\mathrm{HH}$ knowledge (5.6\% had good level $\mathrm{HH}$ knowledge) leaving less chance for proper practices. The risk for patients to develop HCAIs in developing countries is significantly higher than in developed countries [6]. Good $\mathrm{HH}$ practices in developed countries have a crucial role in the prevention of infection in patients. Different studies using WHO instruments have reported a moderate level of $\mathrm{HH}$ knowledge scores, but a low level of good knowledge scores (ranging from 4.3 to 9), especially in developing countries, corresponding to our results [11,14-16]. These results highlight that raising the knowledge level of HCWs should be the primary goal for reaching global patient safety, especially in developing countries.

Our participants graduated from two different educational backgrounds, namely; North Cyprus and Turkey. Interestingly, the group of participants who were educated in Turkey had significantly higher $\mathrm{HH}$ knowledge scores. In Turkey, it was reported previously that nurses ' knowledge level for infection prevention was above the average, but transfer of knowledge to practice was problematic [17]. Another study from Turkey, also reporting low knowledge of $\mathrm{HH}$ and noncompliance to $\mathrm{HH}$ practices and suggesting in-service $\mathrm{HH}$ educations as a significant factor to improve $\mathrm{HH}$ practices among health care personnel including the nurses [16]. Also, poor knowledge of hand washing techniques among nurses was reported with suggestions referring to the need to improve present the undergraduate nursing education program in Turkey $[18,19]$. On the other hand, there is no data referring to $\mathrm{HH}$ or infection prevention knowledge in North Cyprus. With this regard, our study results may question the need of revision in the nursing education programs of both countries. Furthermore, our results suggest country of education as a factor to be taken into consideration for improving $\mathrm{HH}$ practices.
As expected, we found that "in-service education" is significantly related to the overall $\mathrm{HH}$ knowledge scores. This aligns with other studies indicating a positive association between different styles of continuous training activities with $\mathrm{HH}$ knowledge [2023]. Thus, more emphasis needs to be given to regularly update the $\mathrm{HH}$ knowledge of nurses, as this may enhance $\mathrm{HH}$ practices.

Apart from that, in-service education can help nurses to keep their knowledge up to date. Only $19.2 \%$ of our respondents answered correctly when asked about the most frequent source of germs responsible for HCAIs. In a study from India, which used same instruments as ours; $27 \%$ of nurses answered the question about the most frequent source of germs leading to HCAIs, correctly [15]. In another study among nursing students in Sri Lanka, this rate was found to be $26.9 \%$ [24]. The level of knowledge for this specific question was far from being adequate and is lower but comparable with other developing countries like Sri Lanka or India. Moreover, the duration of practice was negatively correlated with the knowledge of the most frequent source of germs responsible for HCAIs. The rate of correct answers given for questions regarding routes of crosstransmission and $\mathrm{HH}$ methodologies were average (Average Knowledge Scores were 58.8\% and $60.21 \%$ respectively), which correlates with the literature.[15,24].

Our participants' perceptions were significantly different across different departments. Nurses who worked in the emergency departments had significantly lower $\mathrm{HH}$ perceptions compared to those working in gynecology, pediatrics and surgery. Likewise, orthopedics and urology nurses had significantly lower perceptions compared to nurses working in surgery departments. Interestingly, a higher perception was observed in nurses educated in North Cyprus in contrast to those educated in Turkey, despite a lower level of $\mathrm{HH}$ knowledge. Also, we noted higher perceptions through increasing working years. Among the nurses, $16.8 \%$ had poor to moderate levels of perception whereas the remaining $83.2 \%$ had a good perception towards HH. Santosaningsih et al. reported the rate of positive perceptions in different groups to be in a range between 69.1 to $98.7 \%$ in a hospital in Indonesia [25]. In Korea, HCWs ' mean score of $\mathrm{HH}$ perception was 75.2 whereas it was 82.52 in our study [26]. We know that, improved $\mathrm{HH}$ compliance is associated with the change of perception toward $\mathrm{HH}$ among medical personnel [27]. Although, mean score is found to be 82.52 in our study, it is still far from the levels in developed countries, which indicates a lack of $\mathrm{HH}$ compliance in our country. To sum up, educational background, working years and high work load seem to be the factors influencing the perceptions of nurses participating in our study. However, different factors and their roles can be considered in further studies.

Our participants perceived $\mathrm{HH}$ to be less important among other patient safety issues. The importance placed on the $\mathrm{HH}$ by colleagues, patients/parents was perceived poorly among $48.8 \%$ of our participants with $95 \%$ CI $[40,57.6]$ and $22.4 \%$ with 95\% CI $[16,29.6]$ respectively. Moreover, leaders/senior managers also had a poor perception of $\mathrm{HH}$. Thus, initially the leaders/senior managers must be trained concerning the importance and effectiveness of alcohol-based hand-rub to 
improve $\mathrm{HH}$ compliance. The availability of alcohol-based hand-rub and promotion of $\mathrm{HH}$ by leaders/senior managers for the improvement of perception, knowledge and practice in $\mathrm{HH}$ plays an essential role [28]. Furthermore, it is important to note that, in addition to the healthcare professionals, patients and parents also play a critical role in their own safety by reminding HCWs to wash their hands as an effort to increase $\mathrm{HH}$ compliance in real life $[29,30]$.

Standardization of in-service education activities will contribute to the quality and effectiveness of healthcare, $\mathrm{HH}$ and HCAI prevention. For this reason, implementation of WHO-multimodal hand hygiene improvement strategies in the developing countries should be considered. Suggested improvements in HCAI prevention strategies in developing countries where WHO guidelines are not implemented, would be (i) organization of educational activities, (ii) implementation of new practices and (iii) evaluation of compliance to $\mathrm{HH}$ practices among nurses and (iv) planning of future works can be beneficial in the transition period.

Improvements on $\mathrm{HH}$ compliance among nurses should start with the proper education of nurses. Moreover, $\mathrm{HH}$ awareness among leaders of health care facilities as well as nurses should be raised. Continuous education which will frequently remind nurses to wash their hands in a proper way is essential. Apart from that, periodical observation activities for $\mathrm{HH}$ practices should be performed.

Our study results are comparable with other studies especially from developing countries. Possibility of (i) a sampling bias as participation to the study was carried out on a voluntary basis, (ii) tendency to over score socially desirable behavior and (iii) unrealistic estimation of their behaviors can be listed as the limitations of this study.

This is the first study in Northern Cyprus documenting the level of knowledge and perceptions towards $\mathrm{HH}$ among nurses. To conclude based on our results, the suggested improvements in $\mathrm{HH}$ compliance among nurses would be to educate and raise the $\mathrm{HH}$ awareness among leaders of health care facilities and the nurses. Following this study, contacting relevant administrators to organize a campaign and trainings on $\mathrm{HH}$ methodologies would be beneficial to raise the awareness of $\mathrm{HH}$ compliance. Follow-up study could be conducted after two years to monitor the success rate of the outcome.

Acknowledgements: The data presented in this manuscript were collected by an undergraduate student group through Introduction to Clinical Skills-2 Research program of our faculty. The authors would like to express their special thanks to this student group for being involved in the data collection step of this manuscript.

\section{Compliance with Ethical Standards}

Ethical Approval: The study was reviewed and approved by Health Subcommittee of Eastern Mediterranean University Research and Publication Ethics Board with decision number 2017/40-58.
Funding: The study was not supported by any funds.

Conflict of Interest: The authors declare that they have no conflict of interest.

Informed Consent: A written informed consent was obtained from each participant.

Authors' Contributions: M.G. and N.I.A. conceived and planned the study, N.I.A performed the analytic calculations. M.G. and N.I.A. wrote the article. Both authors contributed to the final version of the manuscript. M.G. supervised the project.

\section{REFERENCES}

[1] World Health Organization. Health care-associated infections Fact sheet. World Heal Organ [Internet]. 2015;4. Available from: http://www.who.int/gpsc/country_work/gpsc_ccisc_ fact_sheet_en.pdf Accessed on: 11.10.2017.

[2] World Health Organization (Who). Report on the Burden of Endemic Health Care-Associated Infection Worldwide. WHO Libr Cat Data 2011;40.

[3] Shorter E. Ignaz Semmelweis: The etiology, concept, and prophylaxis of childbed fever. Med Hist 1984;28:334.

[4] Larson EL. APIC guideline for handwashing and hand antisepsis in health care settings. Am J Infect Control 1995;23:251-69.

[5] Garner JS, Favero MS. CDC Guideline for handwashing and hospital environmental control, 1985. Infect Control 1986;7:231-43.

[6] World Health Organisation (WHO). WHO Guidelines on Hand Hygiene in Health Care: First Global Patient Safety Challenge Clean Care Is Safer Care. World Health [Internet]. 2009;30:270. Available from: http://whqlibdoc.who.int/ publications/2009/978.924.1597906_eng.pdf Accessed on: 11.10.2017.

[7] Sullivan KM, Dean A, Soe MM. OpenEpi: a web-based epidemiologic and statistical calculator for public health. Public Health Rep [Internet]. Association of Schools of Public Health; 2009;124:471-4. Available from: https://www.ncbi. nlm.nih.gov/pubmed/19445426 Accessed on: 11.10.2017.

[8] Kilpatrick C, Tartari E, Gayet-Ageron A, et al. Global hand hygiene improvement progress: two surveys using the WHO Hand Hygiene Self-Assessment Framework. J Hosp Infect 2018;100:202-6.

[9] World Health Organisation (WHO). Clean Care is Safer CareTools for evaluation and feedback [Internet]. 2009 [cited 2008 Aug 20]. Available from: https://www.who.int/gpsc/5may/ tools/evaluation_feedback/en/ Accessed on 17.10.2017.

[10] Seyed Nematian SS, Palenik CJ, Mirmasoudi SK, Hatam N, Askarian M. Comparing knowledge and self-reported hand hygiene practices with direct observation among Iranian hospital nurses. Am J Infect Control 2017;45:e65-7. doi: 10.1016/j.ajic.2017.03.007

[11] Nair SS, Hanumantappa R, Hiremath SG, Siraj MA, Raghunath P. Knowledge, attitude, and practice of hand hygiene among medical and nursing students at a tertiary health care centre 
in Raichur, India. ISRN Prev Med 2014;2014:608927. doi: $10.1155 / 2014 / 608927$.

[12] Diwan V, Gustafsson C, Rosales Klintz S, et al. Understanding healthcare workers self-reported practices, knowledge and attitude about hand hygiene in a medical setting in rural India. PLoS One 2016;11:e0163347. doi: 10.1371/journal. pone.0163347.

[13] Zakeri H, Ahmadi F, Rafeemanesh E, Saleh LA. The knowledge of hand hygiene among the healthcare workers of two teaching hospitals in Mashhad. Electron Physician 2017;9:5159-65. doi: $10.19082 / 5159$.

[14] Nabavi M, Alavi-Moghaddam M, Gachkar L, Moeinian M. Knowledge, Attitudes, and practices study on hand hygiene among Imam Hossein Hospital's residents in 2013. Iran Red Crescent Med J [Internet]. 2015;17. Available from: http:// www.ircmj.com/?page=article\&article_id=19606 Accessed on: 14.12.2018.

[15] Maheshwari V, Kaore NCM, Ramnani VK, Gupta SK, Borle A, Rituja K. A study to assess knowledge and attitude regarding hand hygiene amongst residents and nursing staff in a tertiary health care setting of Bhopal city. J Clin Diagnostic Res 2014;8:4-7. doi: 10.7860/JCDR/2014/8510.4696.

[16] Aktug Demir N, Kölgelier S, Küçük A, et al. Level of knowledge and compliance to hand hygiene among health care workers. Nobel Med 2013; 9: 104-9.

[17] Tarakcioglu Celik GH, Korkmaz F. Nurses' knowledge and care practices for infection prevention in neutropenic patients. Contemp Nurse 2017;53:143-55. doi: 10.1080/10376.178.2016.1254566.

[18] Akyol AD. Hand hygiene among nurses in Turkey: Opinions and practices. J Clin Nurs 2007;16:431-7. doi: 10.1111/j.13652702.2005.01543.x.

[19] Çelik S, Koçaşli S. Hygienic hand washing among nursing students in Turkey. Appl Nurs Res 2008;21:207-11. doi: 10.1016/j.apnr.2006.12.001.

[20] Sastry AS, Deepashree R, Bhat P. Impact of a hand hygiene audit on hand hygiene compliance in a tertiary care public sector teaching hospital in South India. Am J Infect Control 2017;45:498-501. doi: 10.1016/j.ajic.2016.12.013.

[21] Oh E, Mohd Hamzah HB, Chain Yan C, Ang E. Enhancing hand hygiene in a polyclinic in Singapore. Int J Evid Based Healthc 2012;10:204-10. doi: 10.1111/j.1744-1609.2012.00277.x.
[22] Huang TT, Wu SC. Evaluation of a training programme on knowledge and compliance of nurse assistants' hand hygiene in nursing homes. J Hosp Infect 2008;68:164-70. doi: 10.1016/j. jhin.2007.11.020.

[23] Erichsen Andersson A, Frodin M, Dellenborg L, et al. Iterative co-creation for improved hand hygiene and aseptic techniques in the operating room: experiences from the safe hands study. BMC Health Serv Res 2018;18:2. doi: 10.1186/ s12913.017.2783-1.

[24] Ariyaratne M, Gunasekara T, Weerasekara M, Kottahachchi J, Kudavidanage, BP, Fernando1 S. Knowledge , attitudes and practices of hand hygiene among final year medical and nursing students at the University of Sri Jayewardenepura. Sri Lankan J Infect 2013;3:15-25. doi: 10.4038/sljid.v3i1.4761.

[25] Santosaningsih D, Erikawati D, Santoso S, et al. Intervening with healthcare workers' hand hygiene compliance, knowledge, and perception in a limited-resource hospital in Indonesia: a randomized controlled trial study. Antimicrob Resist Infect Control 2017;6:23. doi: 10.1186/s13756.017.0179-y.

[26] Kim E, Joo M, Baik S, Hong S. P161: Knowledge and perception toward hand hygiene among health - care workers in teaching hospital, Korea. Antimicrob Resist Infect Control [Internet]. 2013;2:P161. Available from: https://aricjournal. biomedcentral.com/articles/10.1186/2047-2994-2-S1-P161 Accessed on: 17.11.2018.

[27] Lee SS, Park SJ, Chung MJ, et al. Improved hand hygiene compliance is associated with the change of perception toward hand hygiene among medical personnel. Infect Chemother 2014;46:165-71. doi: 10.3947/ic.2014.46.3.165.

[28] Saito H, Inoue K, Ditai J, Wanume B, et al. Alcohol-based hand rub and incidence of healthcare associated infections in a rural regional referral and teaching hospital in Uganda ("WardGel" study). Antimicrob Resist Infect Control 2017;6:129. doi: 10.1186/s13756.017.0287-8.

[29] Severinsson E, Holm AL. Patients ' Role in their own safety - A systematic review of patient involvement in safety. Open Journal of Nursing 2015;5:642-53. doi: 10.4236/ ojn.2015.57068.

[30] Alzyood M, Jackson D, Brooke D, Aveyard H. An integrative review exploring the perceptions of patients and healthcare professionals towards patient involvement in promoting hand hygiene compliance in the hospital setting. J Clin Nurs 2018;44:0-3. doi: 10.1111/jocn.14305. 